творческих продуктов. Автор статьи предлагает методы диагностики, содержсащие ситуации реального выбора; ситуачии выбора учебных задач различного уровня; ситуачии выбора по определеннылм критериям; ситуации выбора учебной цฺели, дифференцирования по степени направленности; ситуации выбора по мотивации достижения цели. Прослежена связь между развитием креативных качеств личности учашихся подросткового возраста и ситуащией выбора в учебно-музыкальной деятельности. Сделан вывод, что больиинство респондентов - подростков $(52,6 \%)$ имеют низкий и ниже среднего уровни развития креативных личностных качеств и характеризуются неприятием выбора в нестандартной ситуации или пассивным к нему отношением.

Ключевые слова: диагностика, наблюдение, анкетирование, тестирование, продуктивный метод, ситуации выбора, креативность, учебно-музыкальная деятельность, учащиеся подросткового возраста.

PAN QIANYI. Output Level Diagnostic Methods creativity of students-teenagers in educationalmusical activity.

The article discusses the methodology for diagnosing the output level of creativity development of teenage students in educational and musical activities. In a stating experiment, methods of observation, questionnaires and testing, a method of creating personal creative products by adolescents were used. The author of the article offers diagnostic methods containing situations of real choice; situations of choice of educational tasks at various levels; selection situations according to certain criteria; situations of choosing an educational goal, differentiation according to the degree of orientation; situations of choice for motivation to achieve the goal. The connection between the development of creative personality traits of teenage students and the situation of choice in educational and musical activity is traced. It is concluded that the majority of teenage respondents (52.6\%) have low and below average levels of development of creative personal qualities and are characterized by a rejection of choice in a nonstandard situation or a passive attitude towards it.

Keywords: diagnostics, observation, questionnaires, testing, productive method, situations of choice, creativity, educational and musical activity, teenage students.

DOI: https://doi.org/10.31392/NZ-npu-144.2019.18

УДК 373.5.091

Позняк А. В.

\title{
ОРГАНИЗАЦИОННО-ПЕДАГОГИЧЕСКИЕ УСЛОВИЯ ПЕДАГОГИЧЕСКОЙ ПРОФИЛИЗАЦИИ ОБРАЗОВАТЕЛЬНОГО ПРОЦЕССА В УЧРЕЖДЕНИЯХ ОБЩЕГО СРЕДНЕГО ОБРАЗОВАНИЯ
}

В статье обосновывается актуальность педагогической профилизачии в учреждениях общего среднего образования в современных сочиокультурных условиях. Автор обращается к опыту организации деятельности педагогических классов в Республике Беларусь в условиях введения в 2015 году профильного обучения в стариих классах. Обосновываются основные организаиионно-педагогические условия эффективной педагогической профилизации. Они раскрываются через нормативное правовое, учебнометодическое, организачионно-технологическое и ресурсно-информационное обеспечение. Дана краткая характеристика каюдого из условий. На основе результатов многолетнего мониторинга делается вывод об эффективности применения комплекса рассмотренных условий.

Ключевые слова: профилизаиия, педагогическая профилизация, педагог, педагогические классы, непрерывное педагогическое образование, организачионно-педагогические условия.

(стаття подана мовою орихіналу) 
Как показывает история становления и развития профилизации школьного образования, профильное обучение в школе может быть организовано на основании различных подходов - предметного, разноуровневого, по трудовой сфрере, которым соответствуют различные виды профилизации. Следует отметить, что предметная профилизация прочно закрепилась в мировой образовательной практике. Это связано со спецификой академической профилизации, направленной на достижения учащихся в области изучения отдельных основ наук. В XX веке доминировали сциентистский и знаньевый подходы к отбору и структурированию содержания образования в школе: образование было направлено на приобщение школьников к науке и производству, человек рассматривался как "производительная сила", а наивысшей ценностью считались стиль и общие методы построения знания, свойственные естественным и точным наукам, которые рассматриваются в качестве образца научного знания вообще и др. [1]. В этой связи постоянно совершенствовались подходы, фрормы и методы профильной дифференциации по предметам, обеспечивавшей подготовку учащихся с повышенными способностями и высоким уровнем знаний по профильным предметам [2, с. 34-48]. В то же время социумом всегда была востребована школьная профилизация по сферам социально-трудовой деятельности, гораздо более целенаправленно формирующая готовность учащегося к выбору профессии. В первую очередь это были рабочие профессии. И отечественная, и зарубежная школы пошли по пути знакомства учащихся с основами профессий, создания учебно-производственных комбинатов, приближавших школьное обучение к реальным условиям производства.

В 2015/2016 учебном году в Республике Беларусь на 3-й ступени общего среднего образования вводится профильное обучение. Такая модернизация общего среднего образования позволила в полной мере учесть социокультурные и экономические тенденции развития современного белорусского общества в контексте мировых процессов: целенаправленные усилия государства в области укрепления человеческого капитала белорусского общества [3], укоренение идеи образования через всю жизнь и создание соответствующих условий реализации этой идеи в рамках концепции непрерывности образования [4], обновление содержания образования на принципах личностно ориентированного и компетентностного подходов, актуализирующих как первоочередную задачу поддержки обучающегося в выборе индивидуальной траектории образования, развития и построения на этой основе стратегии своей жизнедеятельности. По утверждению Г.В.Пальчика, профильное обучение позволяет обеспечить более полное удовлетворение образовательных запросов выпускников школ, сорормировать у них готовность к продолжению образования в рамках избранного профиля и в конечном итоге стать залогом успешной трудовой деятельности [5, с. 18].

Организация профильного обучения в старших классах наряду с 
предметной профилизацией предполагает создание профильных классов профессиональной направленности. Обучение в таких классах делает возможным формирование у растущего человека, находящегося в ситуации жизненно важного процесса построения траектории своей самостоятельной взрослой жизни, важнейшие компоненты адекватного выбора профессии: "ясное понимание своих интересов, ресурсов, возможностей, ограничений; знание требований, перспектив, ограничений профессии; взвешенное суждение о соотношении этих двух групп фрактов" [6, с. 123].

В соответствующем инструктивно-методическом письме оговаривается, что “...профильное обучение должно способствовать выявлению и развитию у учащихся необходимых качеств личности и ценностных ориентаций, знаний, умений, навыков, опыта деятельности, связанных с будущей профессиональной деятельностью. В этой связи в рамках профильного обучения в учреждениях общего среднего образования могут функционировать классы профессиональной направленности..." [7]. В рамках профильного обучения в старших классах появляется возможность усиления профориентационной работы, ее интеграции в основной учебный процесс за счет специальных фракультативных курсов и насыщения образовательной среды школы профилизирующими компонентами. Это становится одной из ключевых предпосылок для организации процесса педагогической профилизации в белорусских школах и создания сети профильных классов и групп педагогической направленности.

Особую группу всегда занимали профеессии, имеющие высокую социальную значимость, требующие комплекса специфических личностных качеств и способностей. В ряду таких профессий одно из первых мест занимает профессия педагога. Еще А. Дистервег, П. Ф. Каптерев, И. Песталоцци, Л.Н. Толстой, К.Д. Ушинский и др. в своих трудах подчеркивали необходимость предъявления высоких требований к претендентам на должность учителя, строгого отбора и качественной подготовки будущих педагогов.

В последние десятилетия на фоне снижения престижа педагогической профессии актуализируются исследования в области поиска механизмов и форм привлечения на педагогические специальности мотивированных выпускников школ. В зарубежных публикациях этого периода поднимаются и исследуются внутренние и внешние причины выбора выпускниками школ педагогической профессии, выявляются наиболее значимые мотивы для обучения на педагогических специальностях, декларируется необходимость тщательного многофакторного отбора абитуриентов на данные специальности.

После окончания перестроечного периода, для которого было характерно падение ценности образования в целом и педагогического образования в частности, в первые десятилетия XXI века под влиянием ряда социокультурных факторов в белорусском обществе начинает возрождаться интерес молодежи к педагогической профессии. В числе ключевых 
социокультурных детерминантов профильного обучения педагогической направленности в учреждениях общего среднего образования: потребность общества в повышении престижа педагогической профессии; организация профильного обучения на 3-й ступени общего среднего образования; становление национальной системы непрерывного педагогического образования. В этих условиях в 2015/2016 учебном году по всей Беларуси вновь открываются профильные классы педагогической направленности, так называемые педагогические классы.

Определяя организационно-педагогические условия педагогической профилизации образовательного процесса в учреждениях общего среднего образования, мы исходили из ключевых аспектов данного явления, представленных в виде модели. При моделировании педагогической профилизации были определены нормативный, содержательный, организационный и ресурсный аспекты, каждый из которых для продуктивной реализации на практике требует адекватного обеспечения.

Уточнение и апробация организационно-педагогических условий, обеспечивающих продуктивное функционирование модели педагогической профилизации в учреждениях общего среднего образования, осуществлялись в процессе внедрения педагогической профилизации в школах и гимназиях Республики Беларусь. Период охватывает 2015-2019 годы. Необходимые исходные данные были получены во время встреч с педагогами и руководителями учреждений образования, в которых открыты педагогические классы (группы), проведения научно-методических семинаров, онлайнопросов руководителей, педагогов и учащихся, в результате анализа информационных продуктов субъектов педагогической профрилизации: статей, материалов конференций, отчетов, методических разработок и др. Таким образом, в качестве организационно-педагогических условий педагогической профилизации образовательного процесса в учреждениях общего среднего образования были выделены нормативное правовое, учебно-методическое, организационно-технологическое и ресурсно-информационное обеспечение. Остановимся на каждом подробнее.

Нормативное правовое обеспечение рассматривается как необходимое условие регламентации процесса профильного обучения педагогической направленности в школе с помощью государственных документов, документов учреждений образования и документации, которую ведут субъекты профильного обучения педагогической направленности - руководители, учащиеся, педагоги. В них определяются алгоритм действий по открытию в школе педагогических классов (групп), соответствующие управленческие процедуры и действия всех субъектов педагогической профилизации (администрации, учащихся, педагогов и др.). Так, в ежегодных инструктивнометодических письмах Министерства образования администрации школ и педагогам дается необходимая информация о порядке открытия и утверждения педагогических классов, формах организации таких классов (класс, группа на параллели, межшкольная группа), обязательных условиях 
функционирования педагогических классов (в частности, там устанавливается, что учащиеся, обучающиеся в педагогических классах, в рамках учебных часов изучают учебные предметы на повышенном уровне, как правило, это те учебные предметы, учителями которых они планируют стать в будущем.

В учреждениях общего среднего образования организация педагогической профилизации регламентируется приказами, распоряжениями, комплексно-целевыми программами, планами, положениями, договорами. В школах и гимназиях, в которых были открыты педагогические классы, были разработаны следующие ЦКП: "Организация допрофильной подготовки и развития профильного обучения", "Психологическое сопровождение профильного класса педагогической направленности", "Решение задач педагогической профилизации средствами предметов общеобразовательного цикла”, “Организация допрофильной педагогической подготовки обучающихся в 5-х - 9-х классах”, “Реализация компетентностного подхода в обучении в педагогических классах" и др. Ключевыми характеристиками таких программ являются актуальность, адекватность поставленным целям и задачам, адресность, реалистичность и выполнимость. В практике работы учреждений общего среднего образования, реализующих педагогический профиль, представлены "Положение о профильных классах педагогической направленности”, “Положение о помощнике классного руководителя", “Положение об организации педагогической практики учащихся педагогических классов в период школьных каникул”, “Положение об организации педагогических проб”, различные положения, касающиеся проведения конкурсов, конференций, олимпиад для учащихся и педагогов педагогических классов и др. Важную роль в обеспечении эффрективности процесса педагогической профилизации в школе играют договоры о сотрудничестве. Эти документы позволяют реализовать идею непрерывности педагогического образования, обеспечивая взаимодействие учреждения общего среднего образования, в которых открыты педагогические классы, с различными учреждениями и организациями, чья деятельность так или иначе связана с подготовкой педагогических кадров.

Учебно-методическое обеспечение как условие педагогической профилизации образовательного процесса в школе необходимо для освоения учащимися пропедевтических психолого-педагогических знаний и опыта педагогической деятельности. Это дидактический комплекс, включающий программы курсов фракультативных занятий, разнообразные пособия, интегрирующие пропедевтические знания о педагогической профрессии и позволяющие учащимся педагогических классов в условиях самостоятельной работы, управляемой педагогом, осваивать содержание педагогической профилизации на протяжении допрофильной и профильной подготовки.

Данное условие предполагает реализацию инвариантной части, обязательной для освоения всеми учащимися педагогических классов и групп, 
и вариативного компонента, включающего разнообразный спектр дидактических материалов и разработок в помощь учащимся и педагогам. Содержательным стержнем инвариантной части педагогической профилизации является программа курса фракультативных занятий "Введение в педагогическую профессию" для 10-х и 11-х профильных классов педагогической направленности, утвержденная Постановлением Министерства образования Республики Беларусь от 24 марта 2017 года № 27 [8].

Вариативная часть учебно-методического обеспечения педагогической профилизации образовательного процесса в школе представлена: методическим сопровождением курса фракультативных занятий "Введение в педагогическую профессию”, пособием “Атлас педагогических профессий и ролей”, мультимедийным учебным тренажером по профильной педагогической подготовке для учащихся X-XI классов, рабочими тетрадями для учащихся профильных классов педагогической направленности по курсу факультативных занятий “Введение в педагогическую профессию”, дневником самодиагностики для учащихся профильных классов педагогической направленности, комплексом программ курсов фракультативных занятий (кружков) педагогической направленности для учащихся 5-9-х классов.

Наряду с содержанием педагогической профилизации в школе, отвечающим на вопрос “Чему учить в педагогическом классе?”, не менее важным является поиск ответа на вопрос "Как учить учащихся педагогических классов?". Поэтому организационно-технологическое обеспечение является необходимым условием педагогической профилизации образовательного процесса в учреждениях общего среднего образования. Двойственная структура данного условия предполагает рассмотрение двух аспектов: организационного и технологического. К организационному аспекту относятся этапы педагогической профилизации образовательного процесса и основные направления управленческой деятельности по педагогической профилизации. К технологическому аспекту относится комплекс форм и способов организации образовательного процесса в условиях педагогической профилизации.

Пропедевтический этап (5-й - 9-й классы) - этап допрофрильной педагогической подготовки, который условно можно разделить на два подэтапа: 5-й - 7-й классы - период формирования профильных интересов учащихся и 8-й - 9-й классы - период становления профильных намерений. Цель данного этапа - подготовка учащихся 2-й ступени среднего общего образования к осознанному выбору педагогического профиля в старших классах, создание условий для их успешной адаптации к специфике обучения в педагогических классах и группах и формирование устойчивого положительного отношения к педагогическому труду. На данном этапе создается система педагогической, психологической, информационной и организационной поддержки, включающей работу с тремя категориями субъектов профилизации: учащимися, педагогами, родителями. В 9-м классе учащиеся находятся в ситуации выбора профиля обучения в старших классах, 
поэтому на этапе допрофильной педагогической подготовки особое внимание уделяется психолого-педагогической диагностике, позволяющей оценивать мотивацию и способности учащихся к продолжению обучения в профильном классе педагогической направленности, а также готовность подростков к социальному, профессиональному и жизненному самоопределению в целом.

Основной этап (10-й - 11-й классы) - этап профильной педагогической подготовки. Его цель - создание условий для профессионального самоопределения обучающихся на третьей ступени общего среднего образования и формирования позитивной установки на выбор педагогической профессии. Два года обучения в педагогическом классе направлены на формирование у учащихся внутренней мотивации к педагогической деятельности и на этой основе - выбору дальнейшего образования по педагогическим специальностям, потребности в самопознании и самоопределении, умений конструктивного педагогического общения, саморегуляции поведения и деятельности, развитии своих педагогических способностей.

Последовательная реализация этапов педагогической профилизации придает образовательному процессу новое качество: в школе фрормируется среда, которая педагогизирована по своей сути, где каждый элемент "работает" на создание атмосферы глубокого уважения к педагогическому труду, популяризации профессии педагога.

В ходе опытно-экспериментальной деятельности, а также на основе анализа передовой педагогической практики по организации процесса педагогической профилизации в учреждениях общего среднего образования, все показавшие себя эффеективными способы, использование которых обеспечивает продуктивность процесса подготовки будущих педагогов еще в школе, были структурированы в две группы методов - это методы персонификации педагогических знаний и методы создания профилизирующих ситуаций. Методы персонификации педагогических знаний, активизирующие процессы самостоятельного смысложизненного поиска и самоопределения, и методы создания профилизирующих ситуаций, позволяющие включить учащихся в субъектно значимую, стимулирующую активность и инициативность учебно-познавательную деятельность, в которой наряду со знаниями и представлениями о специфике педагогического труда они осваивают навыки, необходимые для формирования готовности к выбору педагогических профессий.

В числе наиболее эфффективных форм педагогическолй профилизации следует назвать педагогические пробы, в ходе которых учащиеся получают первый осознанный педагогический опыт, погружаясь в реальные или смоделированные педагогические ситуации, сотрудничество школ, в которых открыты педагогические классы и группы, с вузами, осуществляющими подготовку педагогов (экскурсии, дни открытых дверей, проекты "Студент на один день", конкурсы и др.).

В качестве ресурсов, необходимых для успешной педагогической 
профилизации, нами рассматриваются педагогические кадры, а также системная комплексная информационно-коммуникационная поддержка всех субъектов профилизации. Значение мастерства педагогов, работающих в педагогических классах, для создания педагогически ориентированной профилизирующей среды первостепенно. В этой связи важна системная организационно-методическая поддержка педагогов, повышение их квалификации по образовательной программе “Теория и практика деятельности педагогических классов", организация конкурсов методических разработок и обмена опытом, привлечение к участию в конференции "Педагогические классы: опыт и перспективы” и др.

Сайт "Педагогические классы” (pedklassy.bspu.by) является комплексным информационным ресурсом педагогической профилизации, который содержит весь необходимый учебно- и научно-методический контент педагогической профилизации в учреждениях общего среднего образования и выполняет функции виртуальной площадки для сетевого взаимодействия всех участников педагогической профилизации, платформы для обмена передовым педагогическим опытом в режиме сетевого взаимодействия.

Анализ результатов пятилетнего мониторинга внедрения в школах Республики Беларусь модели педагогической профилизации (2015/2016 2019/2020 учебные годы) показал высокую эффрективность комплексного использования нормативного правового, учебно-методического, организационнотехнологического и ресурсно-информационного обеспечения. Мы наблюдаем не только существенные изменения в качестве контингента поступающих на педагогические специальности, но и широкие социокультурные и образовательные эффректы на государственном, институциональном и личностном уровнях, в том числе: популяризацию в обществе педагогической профессии, укрепление уважения к труду педагога, повышение его престижа в обществе; формирование новой генерации педагогов, чьи позитивные установки на педагогическую профессию сформировались еще в период обучения в школе; формирование у подрастающего поколения психологической и педагогической грамотности; благоприятное изменение образовательной среды школ за счет ее педагогизации (целенаправленного изучения специфики педагогического труда, привлечения учащихся педагогических классов к роли помощника педагога, воспитателя, создания педагогически ориентированного информационного и предметного пространства школ и др.) и педагогических вузов за счет обновления содержания и технологий работы с более активными , мотивированными, подготовленными, имеющими пропедевтические психологопедагогические знания и навыки студентами; высокий развивающий потенциал профильной педагогической подготовки в школе, проявляющийся в развитии у учащихся коммуникативных навыков, эмоционального интеллекта, способности к конструктивным межличностным отношениям и управлению конфликтами и др. 


\section{Используеная литература:}

1. Краевский В. В. Содержание образования : вперед к прошлому. Москва : Педагогическое общество России. 2001 [Электронный ресурс]. Режим доступа : http://www.kraevskyvv.narod.ru/papers/co2001.htm. - Дата доступа : 9.07.2018.

2. Пальчик, Г. В. Теоретические и организационно-педагогические основы лицейского образования в Республике Беларусь : дис. ... д-ра пед. наук : 13.00.01 / Г. В. Пальчик. Минск, 2011. 273 л.

3. Национальная стратегия устойчивого социально-экономического развития Республики Беларусь на период до 2030 г. [Электронный ресурс]. Режим доступа : http://www.economy.gov.by/ru/macroeconomy/nacionalnaya-strategiya. - Дата доступа : 12.01.2016.

4. Кодекс Республики Беларусь об образовании [Электронный ресурс]. Режим доступа : http://kodeksy.by/kodeks-ob-obrazovanii. Дата доступа : 13.03.2016.

5. Пальчик Г. В. Организационно-педагогические основы профильного обучения: монографія. Минск : НИО, 2007. 248 с.

6. Рубцова, Н. Е., Леньков С. Л. Психолого-педагогические модели профессионального становления : кросс-культурный анализ // Человек и образование. 2015. № 1. С. 123-128.

7. Инструктивно-методическое письмо Министерства образования Республики Беларусь от 30.05.2016 № 05-20/94 “Об организации в 2016/2017 учебном году допрофильной подготовки и профильного обучения на III ступени общего среднего образования" [Электронный ресурс]. Режим доступа: https://pedklassy.bspu.by/files/docs/tabs/manager/Letter_from_the_Ministry_of_ Defense_and_Prof_in_2016-2017.pdf. Дата доступа : 31.05.2018.

8. Программа курса факультативных занятий "Введение в педагогическую профессию" для 10-х и 11-х профильных классов педагогической направленности [Электронный ресурс]. Режим доступа : https://pedklassy.bspu.by/files/docs/tabs/pedagogy/facultativi/program_introduction.pdf. Дата доступа :21.11.2016.

\section{References:}

[1] Kraevskij V. V. Soderzhanie obrazovaniya : vpered k proshlomu. Moskva : Pedagogicheskoe obshestvo Rossii. 2001 [Elektronnyj resurs]. Rezhim dostupa : http://www.kraevskyvv.narod.ru/papers/co2001.htm. Data dostupa : 9.07.2018.

[2] Palchik, G. V. Teoreticheskie i organizacionno-pedagogicheskie osnovy licejskogo obrazovaniya $\mathrm{v}$ Respublike Belarus : dis. ... d-ra ped. nauk : 13.00.01 / G. V. Palchik. Minsk, 2011. 2731.

[3] Nacionalnaya strategiya ustojchivogo socialno-ekonomicheskogo razvitiya Respubliki Belarus na period do 2030 g. [Elektronnyj resurs]. Rezhim dostupa: http://www.economy.gov.by/ru/ macroeconomy/nacionalnaya-strategiya. - Data dostupa : 12.01.2016.

[4] Kodeks Respubliki Belarus ob obrazovanii [Elektronnyj resurs]. Rezhim dostupa : http://kodeksy.by/kodeks-ob-obrazovanii. Data dostupa : 13.03.2016.

[5] Palchik G. V. Organizacionno-pedagogicheskie osnovy profilnogo obucheniya: monografiya. Minsk: NIO, 2007. $248 \mathrm{~s}$.

[6] Rubcova, N. E., Lenkov S. L. Psihologo-pedagogicheskie modeli professionalnogo stanovleniya : krosskulturnyj analiz // Chelovek i obrazovanie. 2015. № 1. S. 123-128.

[7] Instruktivno-metodicheskoe pismo Ministerstva obrazovaniya Respubliki Belarus ot 30.05.2016 № 0520/94 "Ob organizacii v 2016/2017 uchebnom godu doprofilnoj podgotovki i profilnogo obucheniya na III stupeni obshego srednego obrazovaniya" [Elektronnyj resurs]. Rezhim dostupa: https://pedklassy.bspu.by/files/docs/tabs/manager/Letter_from_the_Ministry_of_Defense_and_Prof_in_2 016-2017.pdf. Data dostupa : 31.05.2018.

[8] Programma kursa fakultativnyh zanyatij "Vvedenie v pedagogicheskuyu professiyu" dlya 10-h i 11-h profilnyh klassov pedagogicheskoj napravlennosti [Elektronnyj resurs]. Rezhim dostupa : https://pedklassy.bspu.by/files/docs/tabs/pedagogy/facultativi/program_introduction.pdf. - Data dostupa : 21.11.2016.

Позняк А. В. Організаційно-педагогічні умови педагогічної профілізацї̈ освітнього процесу у установах загальної середньої освіти.

У статті обтрунтовується актуальність педагогічної профілізації в закладах загальної середньої освіти в сучасних соиіокультурних умовах. Автор звертається до досвіду організаиії діяльності педагогічних класів в Республічі Білорусь в умовах введення в 2015 рочі профільного навчання в старших 
класах. Обгрунтовуються основні організачійно-педагогічні умови ефективної педагогічної профілізації. Вони розкриваються через нормативне правове, навчально-методичне, організачійно-технологічне $i$ ресурсно-інформаційне забезпечення. Дана коротка характеристика кожного з умов. На основі результатів багаторічного моніторингу робиться висновок про ефективність застосування комплексу розглянутих умов.

Ключові слова: Профілізачія, педагогічна профілізація, педагог, педагогічні класи, безперервне педагогічну освіту, організаційно-педагогічні умови

POZNIAK A. V. Organizationally pedagogical terms of the pedagogical profiling of educational process in establishments of universal middle education.

The article substantiates the relevance of pedagogical profiling in institutions of general secondary education in modern sociocultural conditions. The author refers to the experience of organizing the activities of teacher classes in the Republic of Belarus in the context of the introduction in 2015 of specialized education in high school. The basic organizational and pedagogical conditions of effective pedagogical profiling are substantiated. They are disclosed through regulatory legal, educational, methodological, organizational, technological and resource information support. A brief description of each of the conditions is given. Based on the results of many years of monitoring, a conclusion is drawn on the effectiveness of using the complex of conditions considered.

Keywords: Profiling, pedagogical profiling, teacher, teacher classes, continuing teacher education, organizational and pedagogical conditions.

DOI: https://doi.org/10.31392/NZ-npu-144.2019.19

УДК 378. 155.9. 81

Резван О. 0.

\section{АСПЕКТИ ІМІДЖЕВОГО ПІДХОДУ У ПІДГОТОВЦІ ПЕРЕКЛАДАЧІВ}

У статті з'ясовано суть поняття “імідж” у професійному аспекті як образ професї у масовій свідомості; визначено особливості іміджу перекладачів різної функиіональної спрямованості : послідовний перекладач усних текстів, перекладач-синхроніст, перекладач письмових текстів (художніх, наукових, спеціальних), а також опосередкованих та додаткових професій: перекладач-референт, перекладачжурналіст, викладач іноземної мови, перекладач-гід; представлено схему іміджевої підготовки майбутніх перекладачів у процесі навчання, шо реалізується на етапах: сприйняття образу професії, імідж-аналізу, імідж-креативу, імідж-дизайну та імідж-промоушену.

Ключові слова: імідж, перекладач, професія, функиї діяльності перекладача, образ.

Проблеми вибору профресії в умовах надмірної інформатизації сучасного суспільства характеризуються впливом на мотивацію людини різних фракторів, які можуть стати як позитивними, такими, що збуджують природні сили особистості, активізують потенційно важливі їі ресурси, так і негативні, які стосуються зовнішнього тиску на молоду людину, заставляючи їі робити вибір в умовах, коли однозначної спрямованості щодо фраху ще не сформовано. Одним із таких фракторів, який можна розглядати і як позитивний, і як негативний, $є$ імідж профресії, що у сучасному медійному просторі досить чітко пропагується як програма, якої має набути фахівець конкретної професії.

У сучасному науковому дискурсі проблема іміджевого аспекту у створенні 